\title{
The Integrative Model of Behavior Prediction to Explain Technology Use in Post-graduate Teacher Education Programs in the Netherlands
}

\author{
Wilfried Admiraal ${ }^{1}$, Ditte Lockhorst ${ }^{2}$, Ben Smit $^{1} \&$ Sanne Weijers ${ }^{2}$ \\ ${ }^{1}$ Leiden University Graduate School of Teaching, Leiden University, Leiden, the Netherlands \\ ${ }^{2}$ Oberon Research and Consultancy, Utrecht, the Netherlands \\ Correspondence: Wilfried Admiraal, Leiden University Graduate School of Teaching, Leiden University, PO Box 905, \\ 2300 AX Leiden, the Netherlands. Tel: 31-71-527-6081. E-mail: w.f.admiraal@iclon.leidenuniv.nl
}

Received: October 18, 2013

Accepted: November 2, $2013 \quad$ Online Published: November 4, 2013

doi:10.5430/ijhe.v2n4p172

URL: http://dx.doi.org/10.5430/ijhe.v2n4p172

\begin{abstract}
This study examined technology in post-graduate teacher training programs in the Netherlands. A questionnaire was completed by 111 teacher educators from 12 Dutch universities with a post-graduate teacher training program. The general view of the use of technology in Dutch post-graduate teacher education was quite conventional. Basic technology such as computers, WiFi, electronic whiteboards, virtual learning environments and presentation software was commonly used, but more advanced or innovative technology was less common. In addition, the psychological Integrative Model of Behavior Prediction of Fishbein and Azjen was applied to explain differences between teacher educators in the use of both hardware and software in teacher education. Teacher educators' positive attitudes toward technology in education were significantly related to the extent to which hardware facilities were used to support teacher training pedagogy. Perceived norm largely explained differences in the extent to which software applications were used. However, both aspects were moderated by teacher educators' gender and teaching experience showing that female teacher educators and experienced teacher eduactors reported to use technology in teacher education more than other teacher educators. Soft- and hardware conditions and self-efficacy in technology did not add much explanatory power. Implications for technology use in post-graduate teacher training are formulated.
\end{abstract}

Keywords: Technology, Teacher education, Integrative model of behavior prediction

\section{Introduction}

The quality of how technology is addressed in teacher education programs is conditional for how student teachers apply technology in secondary schools after their graduation (Tondeur, Van Braak, Sang, Voogt, Fisser, \& Ottenbreit-Leftwich, 2012). In teacher education programs, technology receives little attention, neither how it can be used in secondary education nor as support of pedagogy in teacher education itself (Chien, Chang, Yeh, \& Chang, 2012). This means that most learning how to teach with technology in secondary education is done during school practice, after student teachers have graduated and entered the profession. More attention to technology in teacher preparation programs might make this learning process of teachers in school practice more efficient and effective.

In order to increase the use of technology in teacher education programs, more information is needed about the current state of affairs of the use of technology in teacher education as well as the variables that explain differences in the use of technology through which changes could be implemented. One of the landmark models used for explaining and predicting behavior is the Integrative Model of Behavior Prediction (Fishbein \& Azjen, 2010). Three variables form the central explanatory variables: Attitudes, Self-efficacy and Perceived norm. Previous research on explaining technology use in teacher education applied other models, which mainly considered technology variables and mostly disregarded psychological variables that might be important in the explanation of differences in the use of technology. In the current study, the Integrative Model of Behavior Prediction was adopted to explain differences in how teacher educators use technology in teacher education in a parsimonious way.

\section{Theoretical Models of Technology in Education}

Many theoretical models have been used to predict or explain differences in technology acceptance, intention to use technology and actual use of technology. The most cited models are the Technology Acceptance Model (TAM; Davis, 1989), and its updated versions TAM2 (Venkatesh \& Davis, 2000) and TAM3 (Vekantesh \& Bala, 2008), the Unified Theory of Acceptance and Use of Technology (UTAUT; Venkatesh, Morris, Davis, \& Davis, 2003) and its successor 
UTAUT2 (Venkatesh, Thong, \& Xu, 2012), and the Integrative Model of Behavior Prediction (Fishbein \& Azjen, 2010).

Given the critical contribution that teachers can make in supporting the integration of computer technology in classrooms, to understand teachers' acceptance of technology becomes crucial. The successful use of technology in teaching and learning depends on the factors that significantly influence teachers' acceptance, intention to use and actual use of technology. One of the first models that included both technological and psychological factors affecting technology acceptance is the Technology Acceptance Model (TAM; Davis, 1989). Rooted on the principles of the Theory of Reasoned Action (TRA; Fishbein \& Azjen, 1975), TAM proposed the perceived usefulness and perceived ease of use to be the fundamental determinants of a teacher's intention to use technology in class. Perceived usefulness refers to the degree to which teachers believe technology supports their teaching in an efficient and productive manner. Perceived ease of use describes the extent to which teachers think that the use of technology will be relatively free of effort. Both perceived usefulness and perceived ease of use jointly affect attitudes toward using technology, whilst perceived ease of use has a direct impact on perceived usefulness. Several studies have provided empirical support for the use of TAM (e.g., Teo, 2009) and other authors suggested to expand TAM with other variables, such as more user factors and environmental factors. These expansions led to TAM2 and TAM3. TAM2 (Venkatesh \& Davis, 2000) also included aspects of social influence and TAM3 (Venkatesh \& Bala, 2008) was broadened with user factors such as self-efficacy and computer anxiety. Despite all of the refinements, TAM was technology oriented and not user oriented, and therefore did not take into account crucial individual psychological processes.

The Unified Theory of Acceptance and Use of Technology (UTAUT; Venkatesh, Morris, Davis, \& Davis, 2003) was designed by synthesizing prior technology-acceptance research. The four key constructs that influence teachers' intention to use a technology and/or technology use were Performance expectancy (the degree to which using a technology will provide benefits to teachers in teaching), Effort expectancy (the degree of ease associated with teachers' use of technology), Social influence (the extent to which teachers perceive that school leader, colleagues, students, etc. believe they should use technology), and Facilitating conditions (which refer to teachers' perceptions of reources and support available to use technology). In UTAUT2, the original model was elaborated with three other key constructs Hedonic motivation (fun or pleasure derived from using technology), Price value (cognitive trade-off between perceived benefits of using technology and the costs for using them), and Habit (the extent to which teachers believe technology use is automatic; Venkatesh, Thong, \& Xu, 2012). All seven constructs are found to have a significant influence on behavioral intention of mobile Internet technology users in Honk Kong (Venkatesh et al., 2012), but only Performance expectancy was (negatively!) related to technology use by US instructors in higher education classes (Lewis, Fretwell, Ryan, \& Parham, 2013). Raman and Don (2013) applied an adapted version of UTAUT2 to preservice teachers' acceptance of Learning Managament Systems (LMS) and reported a direct effect of Facilitating conditions and indirect effects (via Behavioral intention) of Performance expectancy, Effort expectancy, Social influence, Facilitating conditions, and Hedonic motivation on preservice teachers' use of LMS. In general, these were weak to moderate effects, with the exception of Facilitating conditions, which had strong direct effect on technology use. In contrast to Venkatesh et al. (2012), Raman and Don reported large correlations between the seven key constructs which might imply problems with the construct validity of the measurement of UTAUT2 with technology in teacher education.

Kreijns and colleagues (Kreijns, Vermeulen, Kirschner, Van Buuren, \& Van Acker, 2013) proposed to apply the Integrative Model of Behavior Prediction (IMBP; Fishbein \& Azjen, 2010) to explain teachers' willingness to use technology in their pedagogy. IMBP, grounded on the Theory of Reasoned Action (TRA; Fishbein \& Ajzen, 1975) and Theory of Planned Behavior (TPB; Azjen, 1991), was developed and tested in the domain of Health, but was assumed to identify in any given population the factors that deteremine a given behavior in a parsimonious way. Three key constructs (Attitudes, Perceived Norm and Self-efficacy) were hypothesized to influence intention to behavior, that, together with skills and environmental constraints, influences actual behavior. Attitude is the general sense of favorability regarding performing a behavior, and is a function of specific beliefs about the likelihood that performing the behavior will have certain outcomes and an evaluation of these outcomes in terms of good or bad. Perceived norm is a function of beliefs about the level of expected support from members of important social networks (e.g., colleagues), the extent to which these members perform the behavior themselves and the motivation to comply with these referents. Self-efficacy is the perceived capability in specific challenging or facilitating circumstances. Based on a review of research into technology use of teachers, Kreijns et al. (2013) concluded that IMPB provided a parsimonious model to explain factors that influence technology use of teachers. They also suggested that the model should be tested in the domain of technology use as part of teachers' pedagogy, using 
specific indicators of the technology that is used.

In the current study, technology use was studied in post-graduate teaching education in the Netherlands. First, we were interested in the state of the art of technology in teacher training and therefore formulated the following research question:

1) How do hardware facilities and software tools receive attention in post-graduate teacher education in the Netherlands?

Secondly, the Integrative Model of Behavior Prediction was applied to explain differences in the teacher educators' use of technology in teacher education programs. Recent research showed that a limited technology infrastructure and the absence of positive attitudes toward technology in education form the two main constraints of using technology in teacher education programs (Omoogun, Ephraim, \& Omoogun, 2013). These findings align with the outcomes of other studies on technology use in teacher education presenting Facilitating conditions and Attitudes toward technology to be the most significant explanatory variables of technology use in teacher education (cf., Barton \& Haydn, 2006; Drent \& Meelissen, 2008; Raman \& Don, 2013; Tondeur et al., 2012). As we were interested in actual behavior only, we examined direct effects from Facilitating conditions and the three key concepts Attitudes, Perceived norm and Self-efficacy on teacher educators' use of technology. We left out teacher educators' skills and knowledge to use technology because of the assumed overlap with self-efficacy (cf., Teo \& Van Schaik, 2012). Therefore, our second research question was:

2) How are Attitudes toward technology, Self-efficacy in using technology, Perceived norm in technology and Facilitating conditions of technology related to teacher educators' technology use in teacher education programs.

Based on the studies mentioned above two hypotheses were formulated:

H1) Attitudes toward technology, Self-efficacy in using technology and Perceived norm in technology are positively related to technology use in teacher education

H2) Facilitating conditions are positively related to technology use in teacher education

\section{Method}

\subsection{Participants}

Data have been collected in 12 out of the 13 post-graduate teacher education institutions in the Netherlands. A questionnaire was administered with 111 teacher educators providing quantitative data to test the Integrative Model of Behavior Prediction. Of these 111 teacher educators, 55\% were female and many of them were experienced teacher educators ( $24 \%$ with 6-10 years teaching experience and $37 \%$ with more than 10 years teaching experience). Furthermore, four group interviews were carried out with in total 13 teacher educators, 12 student teachers and 5 co-operating school teachers, connected to 4 teacher education programs. These 13 teacher educators also completed the questionnaire.

\subsection{Data and Measures}

The group interviews were focused on how technology was used in teacher education programs, either as a topic or as a support of teacher educators' pedagogy. More specifically, participants were asked to report their opinion about the importance of technology skills for both student teachers and school teachers, how technology was addressed in teacher education programs, how student teachers were prepared to use technology in their teaching in secondary education, and their suggestions to improve teacher preparation of use of technology in secondary education.

In the questionnaire, the presence of hardware and software, the teacher educators' use of hardware and software, and their Attitudes toward technology, Self-efficacy in using technology, and Perceived norm in technology were measured. For measuring the presence of hardware facilities and software tools, participants reported the presence of a list of 10 hardware facilities and 14 software tools on a 4-point Likert-type scale with $1=$ not present and $4=$ present to a large extent. Participants rated their use of hardware and software on the basis of the same list on a 5-point Liker-type scale, with $1=$ (Almost) never to $5=$ (Almost) always. Hardware facilities included, for example, beamers, digital cameras, smartphones and tablets. Examples of software tools were digital portfolio, social media, games and simulations. Attitudes toward technology, Self-efficacy in using technology, and Perceived norm in technology were measured by 21 items that were based on the work of Alberini (2006) and Teo and Van Schaik (2012). After Principal Component Analysis with varimax rotation the measurement of these tree key concepts was optimized: Attitudes toward technology (6 items, Cronbach's $\alpha=0.88$ with, for example, "The use of technology improves my teaching"), Self-efficacy in using technology (7 items, Cronbach's $\alpha=0.93$ with, for example, "I am 
able to use technology in an effective way") and Perceived norm in technology ( 3 items, Cronbach's $\alpha=0.85$ with, for example, "In our institute, technology has an important place in teaching").

Presence of hardware facilities and software applications were grouped into the level of and the variety in hardware facilities and software tools (with a Cronbach's $\alpha=0.72$ for the original hardware scale and a Cronbach's $\alpha=0,87$ for the original software scale). So, this procedure resulted in four variables concerning Facilitating conditions (both level and variety of hardware facilities and software tools).

Two variables concerned the extent to which teacher educators use either hardware facilities (based on 10 items, Cronbach's $\alpha=0.78$ ) or software applications (based on 14 items, Cronbach's $\alpha=0.87$ ).

\subsection{Analyses}

The interviews were transcribed and summarized using the main themes of the interview protocol as headings. For each interview, one researcher was responsible for the transcriptions of the audiotapes, the inductive identification of the main themes, and descriptive results of each theme. To guard against preset interpretations, the resulting themes and their descriptions were discussed until agreement was reached by the three researchers involved in this study (cf., Marble, 1997). In addition to these narrative descriptions of the interview results, stepwise regression analyses were used to analyze the relationships between teacher educators' background, Facilitating conditions, Attitudes toward technology, Self-efficacy in technology, and Perceived norm in technology as explanatory variables and Use of hardware facilities and Use of software tools as dependent variables. For each of the dependend variables, two models were tested: Model 1 included all main effects and in Model 2 the interaction terms were added that referred to interactions between background variables and the explanatory variables of the particular hypothesis that was tested.

\section{Results}

\subsection{Technology Use in Teacher Education}

In general, teacher educators reported that the facilitating conditions in terms hardware facilities and software applications were present at a basic level: all institutions seemed to have computers, WiFi, enough digital cameras, office software and a virtual learning environment, which was most of the time also used as student portfolio. Less present were electronic whiteboards, tablets, pdas, smartphones and voting systems as well as software tools concerning social media, games and simulations.

In the teacher education programs, technology was hardly addressed in courses that focussed on the development of technology skills; technology, both as teaching support and as topic of teaching, was integrated teacher educators' pedagogy. However in the interviews, the participants reported that the way technology was addressed was not a structural part of the program and therefore largely dependant of teacher educators' skills and motivations. Some teacher educators used clips, websites, simulations, digital assessment, Webquests etc. in each of their classes, others only used presentation software and video clips on their electronic whiteboard.

In the interviews, students, teacher educators as well as co-operating teachers reported that they expect teacher education programs to be leading in innovations in teaching in secondary education, but that in the case of technology students learned more in secondary school than in teacher education. This was not only the case for school-specific technology such as the particular virtual learning environment that was used in school, but also for more generic software applications such as games, simulations, Webquests and student portfolios. But the dependency of the school context to learn more about technology in teaching, also might cause problems. For example, one of the participants in the interviews mentioned: "In our school, there are many, most of the times older, teachers who do not model how to use technology in class. So, in that case, students should learn the latest insights in how to use technology in class at the teacher education institute."

There is not only a problem if technology is not enough addressed in schools, but also if a school is an exemplary context of innovative use of technology. The latter would mean that there is mismatch between teaching in schools (which forms $50 \%$ of the teacher education program in the Netherlands) and the institutional program in teacher education. One example that was mentioned by the interviewees was the concept of Flipping the classroom which is implemented in many schools in a intuitive and teacher-grounded way, but not yet part of the teacher education program. The interviewees agreed that it should be the other way around: teacher education should be the place where students can learn the most recent and innovative technology.

\subsection{Adapted Integrative Model of Behavior Prediction}

The results of the stepwise regression analyses are presented in Table 1. Model 1 shows the main effects and Model 2 shows the final model with both the main effects and the significant interaction terms that were part of the particular hypothesis. 
Table 1. Stepwise regression analyses (B coefficients with standard errors between brackets).

\begin{tabular}{|c|c|c|c|c|}
\hline & \multicolumn{2}{|c|}{ Use of hardware facilities } & \multicolumn{2}{|c|}{ Use of software applications } \\
\hline & Model 1 & Model 2 & Model 1 & Model 2 \\
\hline \multicolumn{5}{|l|}{ Background variables } \\
\hline Gender $(1=$ male; $2=$ female $)$ & $0.34(0.11)$ & n.s. & n.s. & n.s. \\
\hline Age & $-0.14(0.07)$ & $-0.16(0.07)$ & n.s. & $-0.15(0.06)$ \\
\hline Teaching experience & $0.18(0.06)$ & n.s. & $0.10(0.05)$ & n.s. \\
\hline \multicolumn{5}{|l|}{ Facilitating conditions } \\
\hline Hardware presence (level) & n.s. & n.s. & n.s. & n.s. \\
\hline Hardware presence (variety) & n.s. & n.s. & n.s. & n.s. \\
\hline Software presence (level) & n.s. & n.s. & $0.36(0.10)$ & $0.38(0.09)$ \\
\hline Software presence (variety) & n.s. & n.s. & n.s. & n.s. \\
\hline
\end{tabular}

\section{Integrative Model of Behavior Prediction}

\begin{tabular}{lcccc}
\hline Atitudes toward technology & $0.25(0.07)$ & n.s. & n.s. & n.s. \\
Self-efficacy in technology & n.s. & n.s. & n.s. & n.s. \\
Perceived norm in technology & n.s. & n.s. & $0.23(0.07)$ & n.s. \\
\hline
\end{tabular}

Significant interaction terms

\begin{tabular}{llccc} 
Gender x Attitudes & -- & $0.08(0.03)$ & -- & -- \\
Teaching experience x Attitudes & -- & $0.05(0.02)$ & -- & -- \\
Teaching experience x Perceived norm & -- & -- & -- & $0.06(0.01)$ \\
\hline Adjusted R & 0.19 & 0.20 & 0.31 & 0.35 \\
Degrees of freedom & 4,106 & 3,106 & 3,106 & 3,106 \\
\hline
\end{tabular}

Note. n.s. means not significant; -- means not included in the analyses.

4.2.1 Hypothesis 1. Attitudes toward technology, Self-efficacy in using technology and Perceived norm in technology With respect to the extent to which hardware facilities were used, Model 1 shows that Attitudes toward technology appeared to be the only explanatory variable from the Integrative Model of Behavior Prediction (IMPB) which significantly explained differences between teacher educators. In addition, all three background variables also significantly explained differences between teacher educators in hardware use. The relationship of Atttudes toward technology with the use of hardware facilities did not changed significantly leaving out the background variables and/or Facilitating conditions. Adding the interaction terms of the three background variables with Attitudes toward technology in Model 2, showed significant interaction effects with gender $(\beta=0.25 ; \mathrm{p}=0.01)$ and teaching experience $(\beta=0.36 ; \mathrm{p}=0.001)$, a replication of the negative main effect of age $(\beta=-0.24 ; \mathrm{p}=0.02)$, and no main effects of Attitudes toward technology, gender and age. Model 2 accounted for $20 \%$ of the total variance in use of hardware facilities. This model specified the earlier finding with respect to Attitudes toward technology in Model 1: Attitudes toward technology appeared to be related to the use of hardware facilities, but only for female teacher educators and teacher educators with many years of teaching experience. In addition, the older teacher educators were, the less they reported to use hardware facilities (age was highly correlated to teaching experience).

With respect to the Use of software tools by teacher educators, Perceived Norms in technology appeared to be the explanatory variable from the IMBP that showed to have a significant relationship in Model 1. The relationship of Perceived norm in technology with the use of software applications did not changed significantly leaving out the background variables and/or Facilitating conditions. Adding the interaction term of teaching experience with Perceived norm in technology, showed a significant interaction effect $(\beta=0.47 ; \mathrm{p}<0.001)$, a main (negative) effect of age $(\beta=-0.23 ; \mathrm{p}=0.01)$, and no main effects of either Perceived norm or teaching experience. Model 2 did not change the results with respect to the level of software presence $(\beta=0.34 ; \mathrm{p}<0.001)$. This model accounted for $35 \%$ of the total variance in use of software applications. The results of Model 2 specified the earlier finding with respect Perceived norm in technology in Model 1: Perceived norm in technology was related to the use of software applications, but only for experienced teacher educators. In addition, the older teacher educators were, the less they reported to use software applications. 
So, the first hypothesis is only partly confirmed: Attitudes toward technology and Perceived norm in technology explained differences in technology use, but were moderated by teacher educators' gender and teaching experience. Female teacher educators and teacher educators with many years of teaching experience who reported positive attitudes toward technology and who believed that technology was commonly used and valued by their colleagues and superiors, reported to use technology in teacher education more than other teacher educators.

\subsubsection{Hypothesis 2. Facilitating conditions}

The results of the regression analyses for Hypothesis 2 are also presented in Table 1 as we did not find significant interaction terms with Facilitating conditions in Model 2. With respect to the extent to which hardware facilities were used, no main effects of Facilitating conditions were found. With respect to the use of software applications, the level of presence of software applications was found to be significantly related: the more software applications were present, the more teacher educators used these $(\beta=0.34 ; \mathrm{p}<0.001)$.

So, the second hypothesis is also only partly confirmed: The level of presence of software applications explained differences in use of these applications, but no effects were found with the three other indicators of Facilitating conditions.

\section{Discussion and Conclusions}

The general view of the use of technology in Dutch post-graduate teacher education was quite conventional. Basic technology such as computers, WiFi, electronic whiteboards, virtual learning environments and presentation software was commonly used, but more advanced or innovative technology was less common. The latter refers to the use of tablets, smartphones, social media, games, and simulations. This notion aligns with recent research on pre-service teachers' perception of the use of instructional teachnology for teaching and learning (cf., Nadelson, Bennett, Gwilliam, Howlett, Oswalt, \& Sand, 2013). In many ways, students learned more about technology in teaching during their practice in secondary schools than at the teacher education institution. In addition to teacher educators' age, both their positive attitudes toward technology in education and perceived norm in technology largely explained differences in the extent to which technology was used to support teacher training pedagogy, but moderated by gender and teaching experience showing that females and experienced teacher educators reported higher levels of technology use. Soft- and hardware conditions and self-efficacy in technology did not add much explanatory power.

With respect to the models presented in the introduction, the total variance that was explained in both teacher educators' use of hardware facilities and their use of software applications was $19 \%$ and $31 \%$, respectively (and $20 \%$ and $35 \%$ including the interaction terms). This is considerably less than what, for example, Venkatesh et al. (2012) claimed in their UTAUT2 model. However in their study on technology use of student teachers, Raman and Don (2013) found that the explanatory variables of the UTAUT2 model explained only $29.5 \%$ of the variance in use of technology (i.c., LMS use behavior). This means the IMBP might be a parsimonious way to get insight into the key concepts that influence technology use in teacher education. In agreement with earlier research (e.g., Tondeur et al., 2012) positive attitudes toward technology seem to be a crucial factor in explaining differences in technology use. In contrast to other studies (cf., Nadelson et al., 2013), the findings of the current study did not support the crucial role of both self-efficacy and facilitating conditions for the use of technology in teaching.

These findings imply that increasing a more positive attitude toward the use of technology, individual as well as collective as in Perceived norm, might be a more fruitful way to stimulate technology in teacher education programs, compared to creating more facilitating conditions. More specific, increasing teacher educators' positive attitudes toward technology seem to be a route to use hardware facilities more and stimulating a more positive work culture with respect to technology might be a way to use software applications more. The moderation by gender and teaching experience implies that these interventions might not work for everyone and different intervention techniques should be used for different groups of teacher educators. Of course, this kind of causal inferences should be examined in future research as the current study was correlational.

Another way to increase the attention for technology in teaching might be to incorporate secondary schools more in teacher training, especially in the area of teaching with technology. This would not only improve the preparation of teachers in the short term, but also might change the teacher educator program in the long term. Probably secondary schools, at least in the Netherlands, have more and more recent insights in the particular hardware and software applications that can be used to support students' learning processes in secondary education.

\section{Acknowledgements}

This project was partly financed by Kennisnet, which is the Dutch national organization to support technology use in primary and secondary education. 


\section{References}

Ajzen, I. (1991). The theory of planned behavior. Organizational Behavior and Human Decision Processes, 50, 179-211. http://dx.doi.org/10.1016/0749-5978(91)90020-T

Alberini, A. (2006). Teachers' attitudes toward information and communication technologies: the case of Syrian EFL teachers. Computers \& Education, 47, 373-398. http://dx.doi.org/10.1016/j.compedu.2004.10.013

Barton, R. \& Haydn, T. (2006). Trainee teachers' views on what helps them to use information and communication technology effectively in their subject teaching. Journal of Computer Assisted Learning, 22, 257-272. http://dx.doi.org/10.1111/j.1365-2729.2006.00175.x

Chien, Y.-T., Chang, C.-Y., Yeh, T.-K., \& Chang, K.-E. (2012). Engaging pre-service science teachers to act as active designers of technology integration: A MAGDAIRE framework. Teaching \& Teacher Education, 28, 578-588. http://dx.doi.org/10.1016/j.tate.2011.12.005

Davis, F. D. (1989). Perceived usefulness, perceived ease of use, and user acceptance of information technology. MIS Quarterly, 13, 319-339. http://dx.doi.org/10.2307/249008

Drent, M., \& Meelissen, M. (2008). Which factors obstruct or stimulate teacher educators to use ICT innovatively. Computers \& Education, 51, 187-199. http://dx.doi.org/10.1016/j.compedu.2007.05.001

Fishbein, M., \& Ajzen, I. (1975). Belief, attitude, intention, and behavior: An introduction to theory and research. Reading, MA: Addison-Wesley.

Fishbein, M., \& Ajzen, I. (2010). Predicting and changing behavior: The reasoned action approach. New York: Psychology Press.

Kreijns, K., Vermeulen, M., Kirschner, P. A., Buuren, H. van, Acker, F. Van. (2013). Adopting the Integrative Model of Behaviour Prediction to explain teachers' willingness to use ICT: a perspective for research on teachers' ICT usage in pedagogical practices. Technology, Pedagogy and Education, 22, 55-71. http://dx.doi.org/10.1080/1475939X.2012.754371

Lewis, C. C., Fretwell, C. E., Ryan, J., \& Parham, J. B. (2013). Faculty use of established and emerging technologies in higher education: A Unified Theory of Acceptance and Use of Technology Perpsective. International Journal of Higher education, 2(2), 22-34. http://dx.doi.org/10.5430/ijhe.v2n2p35

Omoogun, A. C., Ephraim, P. E., \& Omoogun, R. (2013). Impediments to the adoption of information and communication technology (ICT) in teacher preparation programme. International Journal of Education, 5(3), 11-19. http://dx.doi.org/10.5296/ije.v5i3.3713

Marble, S. (1997). Narrative visions of schooling. Teaching and Teacher Education, 13, 55-64. http://dx.doi.org/10.1016/S0742-051X(96)00043-1

Nadelson, L. S., Bennett, D., Gwilliam, E., Howlett, C., Oswalt, S., \& Sand, J. (2013). The intersection of preservice teachers'confidence, perceptions, and ideas for using instructional technology for teaching and learning. International Journal of Higher Education, 2(4), 77-90. URL: http://dx.doi.org/10.5430/ijhe.v2n4p77

Raman, A., \& Don, Y. (2013). Preservice teachers' acceptance of Learning Management Software: An application of the UTAUT2 model. International Educational Studies, 6(7), 157-164. http://dx.doi.org/10.5539/ies.v6n7p165

Teo, T. (2009). Modelling technology acceptance in education: A study of pre-service teachers. Computers \& Education, 52, 302-312. http://dx.doi.org/10.1016/j.compedu.2008.08.006

Teo, T., \& Van Schaik, P. (2012). Understanding the intention to use technology by preservice teachers: An empirical test of competing theoretical models. International Journal of Human-Computer Interaction, 28, 178-188. http://dx.doi.org/10.1080/10447318.2011.581892

Tondeur, J., Braak, J. van, Sang, G., Voogt, J., Fisser, P., \& Ottenbreit-Leftwich, A. (2012). Preparing pre-service teachers to integrate technology in education: A synthesis of qualitative evidence. Computers \& Education, 59, 134-144. http://dx.doi.org/10.1016/j.compedu.2011.10.009

Venkatesh, V., \& Bala, H. (2008). Technology Acceptance Model 3 and a research agenda on interventions. Decision Sciences, 39, 273-315. http://dx.doi.org/10.1111/j.1540-5915.2008.00192.x

Venkatesh, V., \& Davis, F.D. (2000). A theoretical extension of the technology acceptance model: Four longitudinal field studies. Management Science, 46, 186-204. http://dx.doi.org/10.1287/mnsc.46.2.186.11926

Venkatesh, V., Morris, M., Davis, G., \& Davis, F. D. (2003). User-acceptance of Information Technology: Toward a unified view. MIS Quarterly, 27, 425-478.

Venkatesh, V., Thong, J. Y. L., Xu, X. (2012). Consumer acceptance and use of information technology: Extending the Unified Theory of Acceptance and Use of Technology. MIS Quartery, 36, 157-178. 